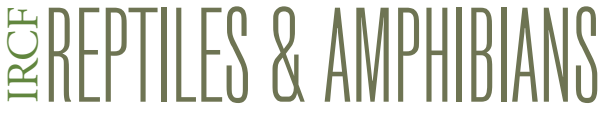 \\ CONSERVATION AND NATURAL HISTORY
}

\section{Limb-loss in a Common House Gecko (Hemidactylus frenatus Duméril and Bibron 1836) from Bangladesh}

Naim Khandakar, Kamrun Nahar Jeny, and Delip K. Das

Department of Zoology, Jagannath University, Dhaka-1100, Bangladesh (naim.jnu.2014@gmail.com)

T he Common House Gecko (Hemidactylus frenatus) is the most common gecko throughout Bangladesh (Khan 2004; Hasan et al. 2014), where it is widely distributed in diverse habitats, including forests and human settlements both in rural and urban areas (IUCN Bangladesh 2015).

At 1728 h on 9 July 2019, we observed a Common House Gecko about $3 \mathrm{~m}$ above the ground on a wall at Luxmibazar $\left(23^{\circ} 42^{\prime} 31.48^{\prime \prime} \mathrm{N}, 90^{\circ} 25^{\prime} 1.30^{\prime \prime} \mathrm{E}\right)$ in Dhaka, Bangladesh. Upon closer observation we noticed that its left forelimb was absent (Fig.1). We were unable to capture the gecko for closer examination (it escaped too quickly despite the missing limb). To the best of our knowledge, this is the first report of limb loss in a reptile from Bangladesh.

\section{Literature Cited}

Hasan, M.K., M.M.H. Khan, and M.M. Feeroz. 2014. Amphibians and Reptiles of Bangladesh - A Field Guide. Arannayk Foundation, Dhaka, Bangladesh.

IUCN Bangladesh. 2015. Red List of Bangladesh Volume 4: Reptiles and Amphibians. IUCN (International Union for Conservation of Nature), Bangladesh Country Office, Dhaka, Bangladesh.

Khan, M.A.R. 2004: Checklist of herpetofauna of Bangladesh. Cobra 75: 1-29.

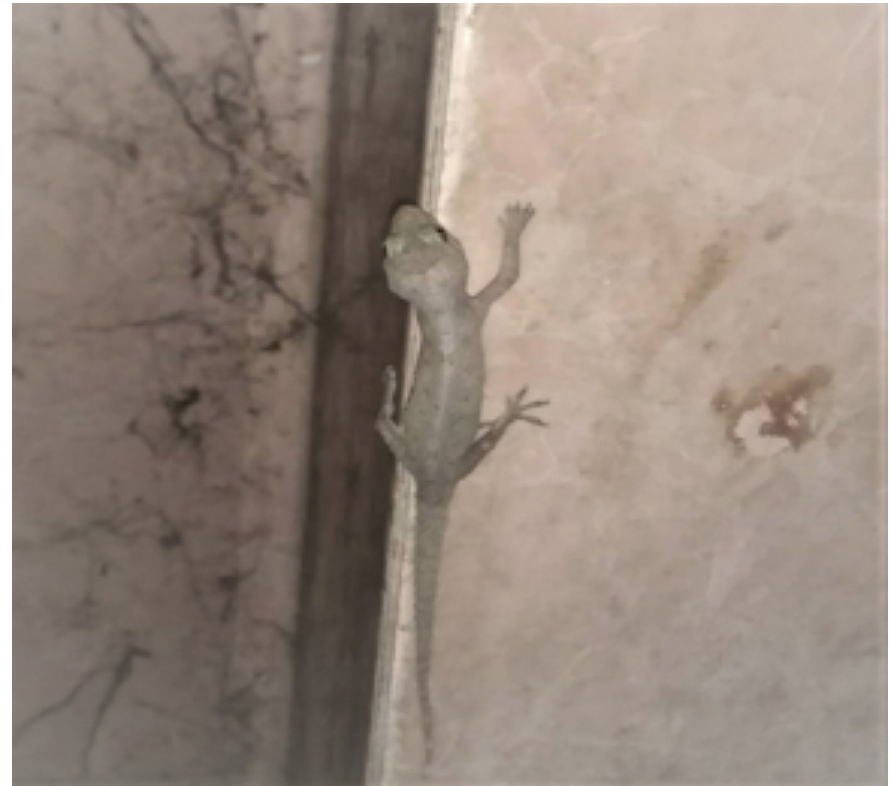

Fig. 1. A Common House Gecko (Hemidactylus frenatus) with missing left forelimb in Dhaka, Bangladesh. Photograph by Naim Khandakar. 